\title{
Article \\ Differential Cutaneous Thermal Sensitivity in Humans: Method of Limit vs. Method of Sensation Magnitude
}

\author{
Yongsuk Seo ${ }^{1}$ and Jung-Hyun Kim ${ }^{2, *}$ \\ 1 Sports AIX Graduate Program, Pohang University of Science and Technology, Pohang 37673, Korea; \\ yseokss@postech.ac.kr \\ 2 Department of Sports Medicine, Kyung Hee University, Yongin-si 17104, Korea \\ * Correspondence: junghyun.kim@khu.ac.kr
}

Citation: Seo, Y.; Kim, J.-H.

Differential Cutaneous Thermal Sensitivity in Humans: Method of Limit vs. Method of Sensation Magnitude. Int. J. Environ. Res. Public Health 2021, 18, 12576. https:// doi.org/10.3390/ijerph182312576

Academic Editor: Paul B. Tchounwou

Received: 3 November 2021

Accepted: 26 November 2021

Published: 29 November 2021

Publisher's Note: MDPI stays neutral with regard to jurisdictional claims in published maps and institutional affiliations.

Copyright: (C) 2021 by the authors. Licensee MDPI, Basel, Switzerland. This article is an open access article distributed under the terms and conditions of the Creative Commons Attribution (CC BY) license (https:/ / creativecommons.org/licenses/by/ $4.0 /)$.

\begin{abstract}
Introduction: The method of limits (MLI) and method of level (MLE) are commonly employed for the quantitative assessment of cutaneous thermal sensitivity. Thermal sensation and thermal comfort are closely related and thermal sensations evoked from the peripheral thermoreceptors play an important role in thermoregulatory response to maintain normal body temperature. The purpose of this study was to compare the regional distribution of cutaneous warm and cold sensitivity between MLI and the method of sensation magnitude (MSM). Method: Twenty healthy men completed MLI and MSM to compare the regional distribution of cutaneous warm and cold sensitivity in the thermal neutral condition. The subjects rested on a bed in a supine position for $20 \mathrm{~min}$. Next, the cutaneous thermal sensitivity of ten body sites was assessed by the means of MLI and MSM for both warmth and cold stimuli. Results: The absolute mean heat flux in MLI and thermal sensation magnitude in MSM showed significantly greater sensitivity to cold than to warm stimulation $(p<0.01)$, together with a similar pattern of regional differences across ten body sites. Both sensory modalities indicated acceptable reliability (SRD\%: 6.29-8.66) and excellent reproducibility (ICC: 0.826-0.906; $p<0.01$ ). However, the Z-sore distribution in MSM was much narrower than in MLI, which may limit the test sensitivity for the detection of sensory disorders and/or comparison between individuals. Conclusion: The present results showed that both MLI and MSM are effective means for evaluating regional cutaneous thermal sensitivity to innocuous warm and cold stimulations to a strong degree of reliability and reproducibility.
\end{abstract}

Keywords: thermoregulation; body temperature; thermal sensation; thermal comfort

\section{Introduction}

Autonomic and behavioral thermoregulation are mediated by afferent inputs from central and peripheral thermoreceptors. In humans, these thermoreceptors consist of two groups: myelinated $\mathrm{A} \delta$-fibers and unmyelinated C-fibers, which respond to cold and warm stimuli, respectively [1,2]. It is generally agreed that the density of thermoreceptors is not uniform, but varied across the body, with a greater overall density of cold receptors than warm receptors [1,2]. Together with the uneven distribution of thermoreceptors, previous findings also suggested that thermal inputs from different body regions are weighed differently by the central nervous system, which may explain regional differences in thermal sensation and thermal comfort under the same degree of thermal stimuli [3].

Thermal sensation and thermal comfort are known to be related closely [4] and are widely used for many bioengineering applications, including sportswear, personal protective clothing, and smart building to improve subjective comfort [5,6]. In particular, thermal sensation evoked from the peripheral thermoreceptors plays an important role in mediating thermoregulatory behavior to maintain normal body temperature and provides the first line of defense against thermal injuries and illnesses. Therefore, the assessment of thermoreceptor sensitivity is of importance in evaluating individuals' behavioral- 
thermoregulation ability as well as evaluating aging- and disease-related deterioration in thermal sensory function.

For the quantitative assessment of cutaneous thermal sensitivity, two types of psychophysical techniques are commonly employed: the method of limits (MLI) and the method of level (MLE) in which the sensation threshold is determined based on subjects' ability to react in response to given thermal stimuli. The basic principles, including the advantages and limitations of the two test methods, are well elucidated in previous research [7-9]. However, in addition to the fundamental limitations of psychophysical approaches, the question of which of the two methods better assesses human cutaneous thermal sensitivity is the subject of an ongoing debate. Previous studies reported drawbacks for MLI compared to MLE in terms of accuracy $[8,10,11]$, whereas others found no significant difference in accuracy [12], or repeatability between the two methods $[9,13,14]$.

More recent studies [15-17] investigating differential cutaneous thermal sensitivity across different body regions utilized a method similar to MLE in terms of applying a constant thermal stimulation. However, the method differs in that the main outcome is a sensation magnitude (MSM) using a subjective scale rather than a threshold detection. Although regional differences in cutaneous thermal sensitivity reported by this modified version of MLE are similar to those found by MLI, to the best of our knowledge, no prior study has compared the two methods.

Because of the aforementioned advantages and limitations of the two test methods (MLE and MLI), it is important to evaluate the valid and reliable measures of the most efficient (validity and reliability) testing procedure. Therefore, the purpose of this study was to compare the regional distribution of cutaneous warm and cold sensitivity between MLI and MSM. It was hypothesized that MLI and MSM would show a similar pattern of thermal sensitivity for warm and cold stimuli across the body.

\section{Material and Methods}

\subsection{Participants}

Twenty healthy men (age: $23.1 \pm 2.1$ years; height: $176.7 \pm 4.5 \mathrm{~cm}$; weight: $76.6 \pm 4.5 \mathrm{~kg}$ ) volunteered to participate in this study. The participants' health condition was reviewed by a health questionnaire and those with a previous history of neurological or sensory disorders were excluded from the study. Before study participation, both written and oral consent were obtained from all the participants and the study protocol was approved by the Institutional Review Board (KHGIRB-19-286).

\subsection{Experimental Procedure}

The participants visited the testing laboratory on three occasions, separated by at least $48 \mathrm{~h}$, for one familiarization and two experimental participations. For the study participation, they were asked to arrive at the testing laboratory at the same time of morning or afternoon, while abstaining from any strenuous activities that may affect their body temperature, such as exercise at least $12 \mathrm{~h}$ before a scheduled visit. The participants were also instructed to abstain from strenuous exercise, caffeine, and alcohol for at least $24 \mathrm{~h}$ before each experimental trial.

For the experimental trials, the participants wore athletic shorts and were instrumented with skin thermistors (ITP082-25, Nikkiso-Therm Co., Ltd. Tokyo, Japan) on ten body regions (forehead, neck, chest, abdomen, shoulder, forearm, hand, thigh, shin, and foot) where cutaneous thermal sensitivity was measured. Next, they rested on a bed in a supine position for $20 \mathrm{~min}$ followed by a measurement of the resting core body temperature using an infrared tympanic membrane thermometer (Welch/Allyn Pro 4000, Hill-Rom Holdings, Inc. Chicago, IL, USA). Upon the completion of the experimental preparation, the participants' cutaneous thermal sensitivity in each region was assessed by means of MLI and MSM for either warmth or cold sensitivity. The order of the test methods and measurements across the body regions was counterbalanced, and warmth and cold sensitivity 
tests were undertaken on a separate day to minimize the transient effect of bidirectional thermal stimuli on the body.

The measurements of cutaneous thermal sensitivity via MLI and MSM were performed using a thermoception analyzer (Intercross-210, Intercross Co., Tokyo, Japan). The analyzer is equipped with a thermal stimulator built with a Peltier element $(2.5 \times 2.5 \mathrm{~cm})$ for thermoelectric cooling and heating, which also measures heat flux between the stimulator and skin surface.

For the MLI, the stimulator was first stabilized to the skin temperature of each measurement site within a range of heat flux at $\pm 30 \mathrm{~W} / \mathrm{m}^{2}$. After stabilization, the stimulator temperature was either increased or decreased at $0.1^{\circ} \mathrm{C} \cdot \mathrm{s}^{-1}$ until the participants perceived a warm or a cold sensation, at which point they pressed a hand-held switch. The sensitivity was determined as a heat flux difference $\left(\mathrm{W} / \mathrm{m}^{2}\right.$ in an absolute value) between the resting state and the perception of warm or cold stimuli. Therefore, the lower the heat flux difference, the greater the cutaneous thermal sensitivity.

For the MSM, the stimulator temperature was set at either 20 or $40{ }^{\circ} \mathrm{C}$ for cold and warm stimuli, respectively. These temperature ranges were chosen based on previous findings of innocuous thermal stimuli without pain [15-17]. The stimulator was placed onto each skin site for $10 \mathrm{~s}$ while the temperature was kept constant. Next, the participants were asked to indicate the level of their temperature sensation using an 11 level scale (0: Not cold/hot; 0: Extremely cold/hot) adopted from previous studies [18].

The measurements of cutaneous thermal sensitivity by means of MLI and MSM were duplicated with a $10 \mathrm{~min}$ rest between the tests to minimize temperature perception bias from the previous measurement and the average values were used for the analyses. All the experimental tests were carried out in a thermoneutral environment (ambient temperature: $25^{\circ} \mathrm{C}$; relative humidity: $50 \%$ ).

\subsection{Statistical Analyses}

The smallest real difference (SRD) was calculated to determine the reliability of each test method [19]. The SRD was utilized to determine the measurement error [7]. When the SRD \% is less than 30\%, the measurement error is acceptable [20]. Furthermore, a pairwise comparison with least significant differences (LSD) was conducted to determine the ranking of the regional sensitivity. Intra-class correlation coefficients (ICC) were used to determine the reproducibility of the repeated measurements for each test method. The ICC value was considered as follows: below $0.4=$ poor reliability; between 0.40 and $0.59=$ fair; between 0.60 and $0.74=$ good; and between 0.75 and $1.00=$ excellent reliability [21].

Finally, two-way analysis of variance (ANOVA) was performed for cutaneous warm and cold sensitivity to determine whether differences existed between the two methods. For this purpose, the MLI and MSM data were converted to Z-scores due to the unit difference between the methods. A statistical significance was set at $p<0.05$ and all the statistical analyses were performed using the SPSS software package (v. 25.0, IBM, NY, USA).

\section{Results}

The absolute mean heat flux in the MLI was significantly lower by $167 \mathrm{~W} / \mathrm{m}^{2}$ for cold sensitivity compared to warm sensitivity. Similarly, thermal sensation in the MSM was significantly higher by 1.6 points for cold sensitivity compared to warm sensitivity, indicating greater cutaneous sensitivity to cold stimuli (Table 1). The smallest real difference percentage was slightly lower in the MLI than in the MSM for both the warm and the cold sensitivity tests; however, all the values were below $10 \%$, indicating an acceptable random measurement error, and, thereby, the acceptable reliability of each method (Table 1). The intra-class correlation coefficients for both MLI and MSM were above.80 $(p<0.001)$ on both the warm and cold sensitivity tests; therefore, the reproducibility of each method was found to be excellent (Table 1). 
Table 1. Mean absolute thermal sensitivity, reliability, and reproducibility between the method of limit and method of sensation magnitude.

\begin{tabular}{|c|c|c|c|c|}
\hline & \multicolumn{2}{|c|}{ MLI } & \multicolumn{2}{|c|}{ MSM } \\
\hline & Warm & Cold & Warm & Cold \\
\hline Mean \pm SD & $924.7 \pm 324.3^{*}$ & $757.7 \pm 243.2^{*}$ & $3.6 \pm 1.6^{*}$ & $5.2 \pm 1.8^{*}$ \\
\hline 95\% CI (upper-lower) & $879.5-969.9$ & $723.8-791.7$ & $3.4-3.9$ & $4.9-5.5$ \\
\hline Standard error & 22.93 & 17.20 & 0.11 & 0.13 \\
\hline Smallest real difference & 63.56 & 47.68 & 0.32 & 0.37 \\
\hline SRD \% & 6.87 & 6.29 & 8.66 & 7.09 \\
\hline Intra-class correlation & $0.826^{* *}$ & $0.839 * *$ & 0.906 * & $0.878^{* *}$ \\
\hline
\end{tabular}

*: Significant difference between warm and cold sensitivity tests at $p<0.01 .{ }^{* *}$ : Significant at $p<0.001$.

No significant interaction was found in warm sensitivity between the MLI and MLE ( $F=2.899, p=0.105)$, nor for the main effect of the method, although differences were found across the body regions $(\mathrm{F}=34.267, p<0.001)$. Similarly, no significant interaction was found in the cold sensitivity between the MLI and MLE ( $F=2.757, p=0.068)$, nor for the main effect of the method, although differences were found across the body regions $(\mathrm{F}=37.262, p<0.001)$ (Figure 1).

(A) Method of Limit

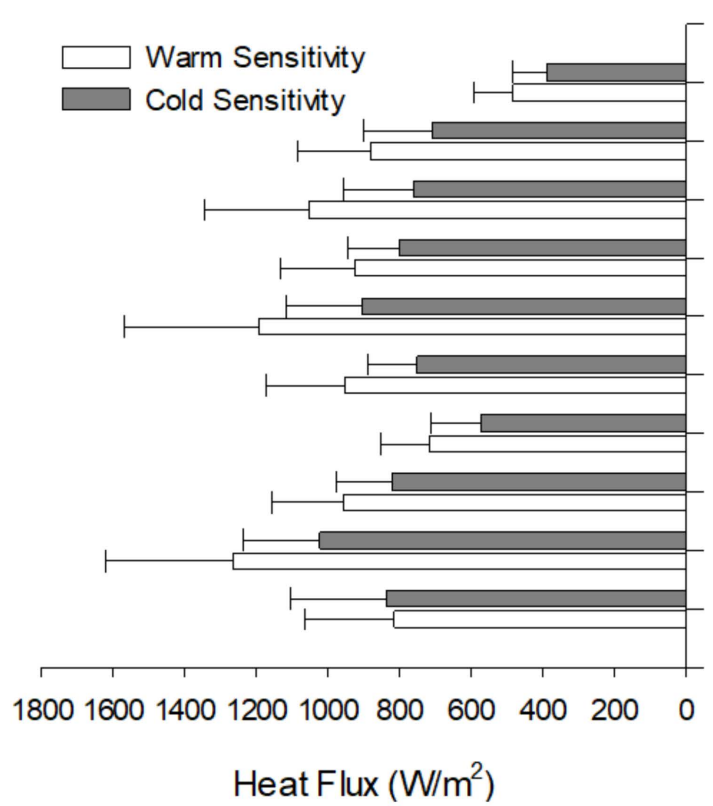

(B) Method of Sensation Magnitude

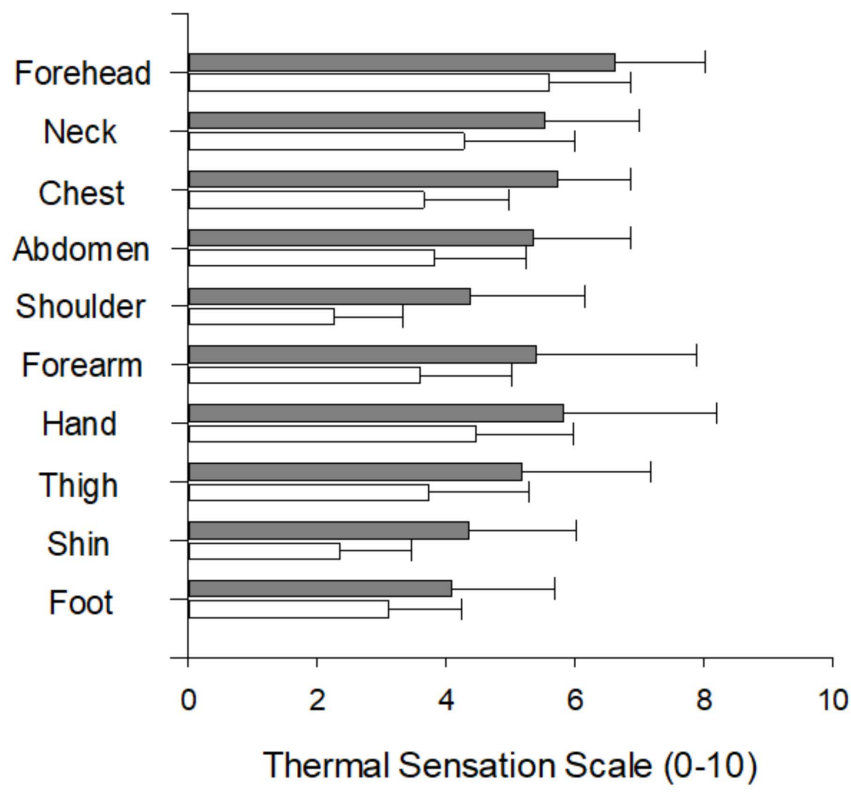

Figure 1. Comparison of warm and cold sensitivity of ten body regions between the method of limit and method of level.

The pairwise comparison showed that the forehead was the most sensitive to both warm and cold stimuli regardless of the test method $(p<0.01)$. Further, the average Z-score was not significantly different between the MLI and MSM for both warm and cold sensitivity; however, the MSM showed a much narrower z-score distribution for cold sensitivity than the MLI (Figure 2). 
(A) Warm Sensitivity

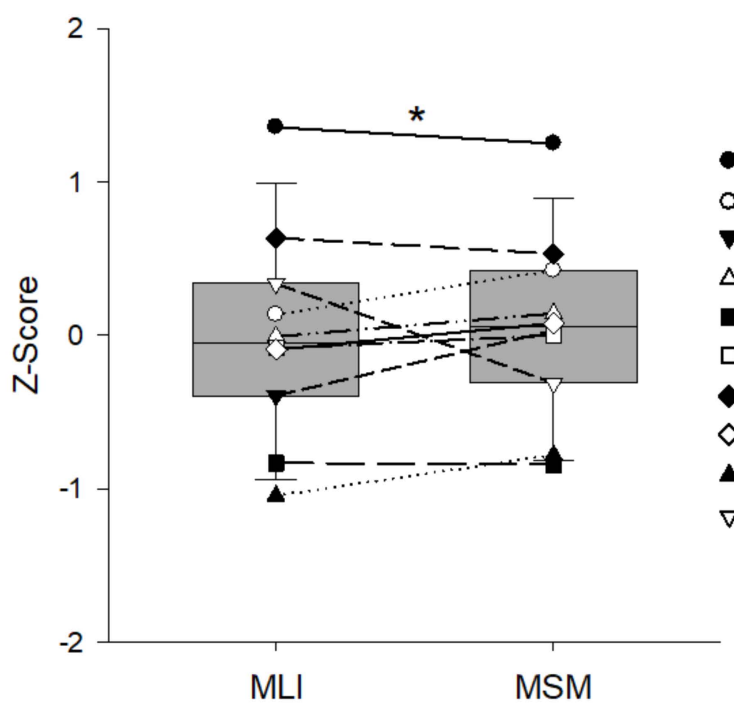

(B) Cold Sensitivity

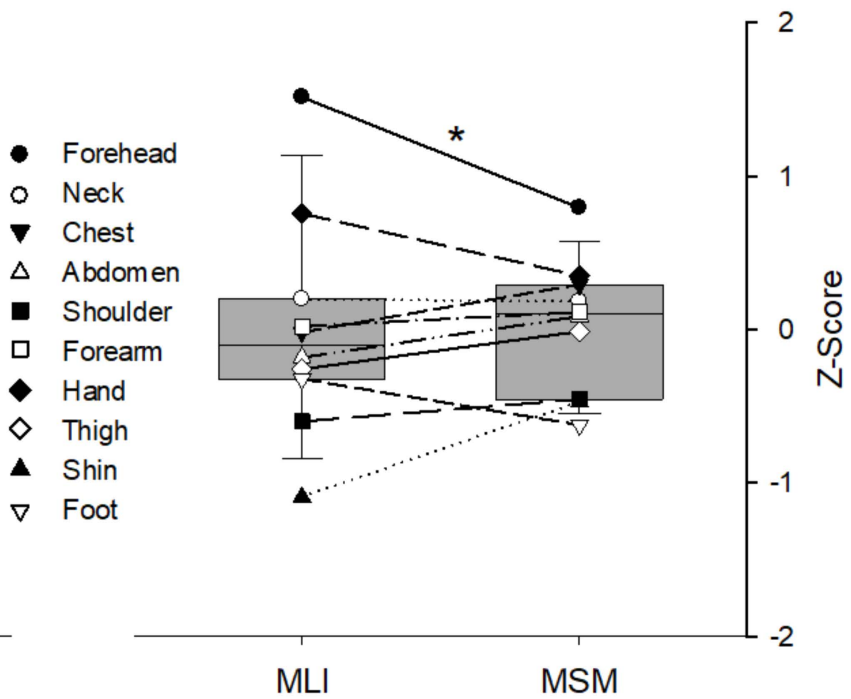

Figure 2. Standard score (Z-score) of warm and cold sensitivity between the method of limit and method of level across ten body regions. *: The forehead was the most sensitive to both warm and cold stimuli regardless of the test method ( $p<0.01)$.

\section{Discussion}

The present study showed that the absolute mean heat flux in the MLI was significantly lower during cold than warm stimulation and, similarly, a significantly greater thermal sensation magnitude was obtained with the cold stimulation in the MSM. These results are in agreement with previous findings of greater cutaneous thermal sensitivity to cold stimulation, which were attributed either singly or in combination to higher density [22], and/or to the faster rate of neural impulses of cold receptors [23,24]. Therefore, the differential sensitivity assessment of warm and cold stimulation by each sensory modality showed similar results, together with acceptable reliability and excellent reproducibility (Table 1), in the present comparison.

In the results reported in this study, regional differences in thermal sensitivity within the body were also observed, with the forehead being the most sensitive to warm/cold stimulation in both methods. This was not unexpected; it agrees with previous findings [3,25,26], probably due to differences in site-dependent thermoreceptor density [27], skin types (e.g., glabrous and non-glabrous) [28], and/or central processing [29].

Although a ranking order of regional sensitivity across the body showed a similar trend between the methods (Figure 1), the Z-score distribution for the warm/cold sensitivity tests differed between the methods in that the MSM values were more narrowly dispersed than the MLI values, especially for cold sensitivity (Figure 2). This may have been due to the fixed degree of thermal stimulation $\left(20\right.$ and $40^{\circ} \mathrm{C}$ for cold and warm, respectively) being too high to discern small differences between the regions and/or an intrinsic limitation for the assessment of thermal sensation magnitude using a categorical scale in the MSM. Further, this discrepancy may have resulted from anatomical features and properties, since these two methods rely on psychophysical perception [30]. Indeed, the forehead is located near the brain and is well vascularized with a thin layer of subcutaneous fat to maintain brain temperature [31]. A previous study reported that the forehead reached the highest mean temperature during thermoneutral, passive heating, and exercise in hot conditions [32]. Therefore, notably reduced sensation magnitude distribution may be a potential limitation when used to detect sensory disorders when comparing between healthy and diseased individuals [33].

It is worthy to note that MSM in the present study is somewhat different from the conventional MLE, which also assesses the thermal detection threshold in a reaction-time- 
exclusive manner similar to that of the MLI in a reaction-time-inclusive manner. The conventional MLE often requires as many as 10 performances to assess the threshold, which, in return, may provide more accurate results $[7,8,10,11]$, while the MLI is favored for its faster and more convenient procedure than the MLE, with acceptable reliability for clinical use.

However, in the tests reported in this study, the MLI required more time to obtain an outcome value due to the skin temperature stabilization and thermal stimulation (rates of temperature change), but provided objective threshold data in the form of heat flux and temperature, which can be established and utilized as normative data for a population of interest. On the other hand, the MSM was carried out for a controlled period of $10 \mathrm{~s}$ for all the body regions, followed by the participants' judgment of sensation magnitudes. Although the MSM procedure was faster than the MLI, procedural concerns were initially raised regarding temperature perception bias due to adaptive changes to constant thermal stimulation and a judgment bias for the selection among the interval scale. No direct analyses were possible to investigate these concerns; however, the fact that the pattern of regional sensitivity to warm/cold stimulation and these variances in MSM were similar to those in the MLI supports its usability for quantitative sensory testing, especially for the assessment of regional differences.

Some caution is advised for the interpretation of the present findings. First, the present study tested only young, healthy men; therefore, the results may differ from other populations when considering the previously reported effects of gender [7,15] and aging [34] on cutaneous thermal sensitivity. Second, the demonstrated data from the MSM should be interpreted concerning the specific thermal stimulation carried out in this study, which appears to be useful for determining regional differences within individuals but may not be effective at detecting functional disorders between individuals. Lastly, both methods tested in this study were carried out by stimulating a small body area via thermal conduction; therefore, stimulating a larger region of the body parts may yield different results.

\section{Conclusions}

The MLI, used in a reaction-time-inclusive manner, required a longer time to attain results, but threshold values were objectively evaluated more objectively. At the same time, the MSM, used in a reaction-time-exclusive manner using constant stimuli with a sensation magnitude scale, was more intuitive to utilize and yet provided similar results to the MLI for differential regional cutaneous sensitivity. One major limitation noted for the MSM was in the comparison between individuals by establishing normative data. Since the psychophysical approach for thermal sensory testing is to quantitatively assess one's reaction to thermal stimulation and thereby assess a link between somatosensory afferents and subjective perception, any test may be subject to some degree of perceptual, psychological, and/or procedural bias. The results presented in this study demonstrated that both the MLI and the MSM are effective means of evaluating regional cutaneous thermal sensitivity to innocuous warm and cold stimulations to a strong degree of reliability and reproducibility.

Author Contributions: Conceptualization, J.-H.K. and Y.S.; methodology, J.-H.K. and Y.S.; analysis, J.-H.K. and Y.S.; investigation, J.-H.K.; writing-original draft preparation, J.-H.K. and Y.S.; writing-review and editing, J.-H.K. and Y.S.; supervision, J.-H.K. All authors have read and agreed to the published version of the manuscript.

Funding: This work was supported by a grant from Kyung Hee University in 2019 (KHU-20191035).

Institutional Review Board Statement: The study was conducted according to the guidelines of the Declaration of Helsinki and approved by Kyung Hee University, South Korea (KHGIRB-19-286).

Informed Consent Statement: Informed consent was obtained from all participants involved in the study. 
Data Availability Statement: The data presented in this study are available on request from the corresponding author. The data are not publicly available due to the protection of personal information.

Acknowledgments: The authors thank the study participants, who generously volunteered their time to engage in the present study.

Conflicts of Interest: The authors declare no conflict of interest.

\section{References}

1. Filingeri, D.; Zhang, H.; Arens, E.A. Characteristics of the local cutaneous sensory thermoneutral zone. J. Neurophysiol. 2017, 117, 1797-1806. [CrossRef]

2. Hensel, H. Thermoreception and temperature regulation. Monogr. Physiol. Soc. 1981, 38, 1-321.

3. Nakamura, M.; Yoda, T.; Crawshaw, L.I.; Kasuga, M.; Uchida, Y.; Tokizawa, K.; Nagashima, K.; Kanosue, K. Relative importance of different surface regions for thermal comfort in humans. Graefe's Arch. Clin. Exp. Ophthalmol. 2013, 113, 63-76. [CrossRef]

4. Nakamura, M.; Yoda, T.; Crawshaw, L.I.; Yasuhara, S.; Saito, Y.; Kasuga, M.; Nagashima, K.; Kanosue, K. Regional differences in temperature sensation and thermal comfort in humans. J. Appl. Physiol. 2008, 105, 1897-1906. [CrossRef]

5. Coull, N.A.; West, A.M.; Hodder, S.G.; Wheeler, P.; Havenith, G. Body mapping of regional sweat distribution in young and older males. Graefe's Arch. Clin. Exp. Ophthalmol. 2021, 121, 109-125. [CrossRef]

6. Flouris, A.D. Functional architecture of behavioural thermoregulation. Graefe's Arch. Clin. Exp. Ophthalmol. 2010, 111, 1-8. [CrossRef]

7. Lue, Y.-J.; Shih, Y.-C.; Lu, Y.-M.; Liu, Y.-F. Method of Limit and Method of Level for Thermal and Pain Detection Assessment. Int. J. Phys. Ther. Rehabil. 2017, 3, 1-5. [CrossRef] [PubMed]

8. Yarnitsky, D.; Sprecher, E. Thermal testing: Normative data and repeatability for various test algorithms. J. Neurol. Sci. 1994, 125, 39-45. [CrossRef]

9. Moloney, N.A.; Hall, T.; Doody, C.M. Reliability of thermal quantitative sensory testing: A systematic review. J. Rehabil. Res. Dev. 2012, 49, 191-207. [CrossRef] [PubMed]

10. Kemler, M.A.; Reulen, J.P.; van Kleef, M.; Barendse, G.A.; Wildenberg, F.A.V.D.; Spaans, F. Thermal thresholds in complex regional pain syndrome type I: Sensitivity and repeatability of the methods of limits and levels. Clin. Neurophysiol. 2000, 111, 1561-1568. [CrossRef]

11. Yarnitsky, D.; Ochoa, J.L. Differential Effect of Compression-Ischaemia Block on Warm Sensation and Heat-Induced Pain. Brain 1991, 114, 907-913. [CrossRef]

12. Levy, D.; Abraham, R.; Reid, G. A comparison of two methods for measuring thermal thresholds in diabetic neuropathy. J. Neurol. Neurosurg. Psychiatry 1989, 52, 1072-1077. [CrossRef]

13. Muijser, H.; Hooisma, J.; Hoogendijk, E.M.G.; Twisk, D. Vibration sensitivity as a parameter for detecting peripheral neuropathy, Results in healthy workers. Int. Arch. Occup. Environ. Health 1986, 58, 287-299. [CrossRef] [PubMed]

14. Gerr, F.E.; Letz, R. Reliability of a widely used test of peripheral cutaneous vibration sensitivity and a comparison of two testing protocols. Occup. Environ. Med. 1988, 45, 635-639. [CrossRef]

15. Gerrett, N.; Ouzzahra, Y.; Coleby, S.; Hobbs, S.; Redortier, B.; Voelcker, T.; Havenith, G. Thermal sensitivity to warmth during rest and exercise: A sex comparison. Graefe's Arch. Clin. Exp. Ophthalmol. 2014, 114, 1451-1462. [CrossRef] [PubMed]

16. Ouzzahra, Y.; Havenith, G.; Redortier, B. Regional distribution of thermal sensitivity to cold at rest and during mild exercise in males. J. Therm. Biol. 2012, 37, 517-523. [CrossRef]

17. Gerrett, N.; Ouzzahra, Y.; Redortier, B.; Voelcker, T.; Havenith, G. Female thermal sensitivity to hot and cold during rest and exercise. Physiol. Behav. 2015, 152, 11-19. [CrossRef]

18. Temel, M.; Johnson, A.A.; Havenith, G.; Arnold, J.T.; West, A.M.; Lloyd, A.B. An examination of five theoretical foundations associated with localized thermosensory testing. Graefe's Arch. Clin. Exp. Ophthalmol. 2021, 121, 1943-1954. [CrossRef] [PubMed]

19. Hopkins, W.G. Measures of Reliability in Sports Medicine and Science. Sports Med. 2000, 30, 1-15. [CrossRef] [PubMed]

20. Huang, S.-L.; Hsieh, C.-L.; Lin, J.-H.; Chen, H.-M. Optimal scoring methods of hand-strength tests in patients with stroke. Int. J. Rehabil. Res. 2011, 34, 178-180. [CrossRef]

21. Cicchetti, D.V. Guidelines, criteria, and rules of thumb for evaluating normed and standardized assessment instruments in psychology. Psychol. Assess. 1994, 6, 284. [CrossRef]

22. Adair, R.K. A model of the detection of warmth and cold by cutaneous sensors through effects on voltage-gated membrane channels. Proc. Natl. Acad. Sci. USA 1999, 96, 11825-11829. [CrossRef]

23. Darian-Smith, I.; Johnson, K.O.; Dykes, R. “Cold” fiber population innervating palmar and digital skin of the monkey: Responses to cooling pulses. J. Neurophysiol. 1973, 36, 325-346. [CrossRef] [PubMed]

24. Darian-Smith, I.; Johnson, K.O.; LaMotte, C.; Shigenaga, Y.; Kenins, P.; Champness, P. Warm fibers innervating palmar and digital skin of the monkey: Responses to thermal stimuli. J. Neurophysiol. 1979, 42, 1297-1315. [CrossRef]

25. Ciuha, U.; Mekjavic, I.B. Regional thermal comfort zone in males and females. Physiol. Behav. 2016, 161, 123-129. [CrossRef] [PubMed]

26. Frank, S.M.; Raja, S.N.; Bulcao, C.F.; Goldstein, D.S. Relative contribution of core and cutaneous temperatures to thermal comfort and autonomic responses in humans. J. Appl. Physiol. 1999, 86, 1588-1593. [CrossRef] [PubMed] 
27. Burke, W.E.; Mekjavic, I. Estimation of regional cutaneous cold sensitivity by analysis of the gasping response. J. Appl. Physiol. 1991, 71, 1933-1940. [CrossRef]

28. Essick, G.; Guest, S.; Martinez, E.; Chen, C.; McGlone, F. Site-dependent and subject-related variations in perioral thermal sensitivity. Somatosens. Mot. Res. 2004, 21, 159-175. [CrossRef]

29. Dyck, P.J.; Zimmerman, I.; Gillen, D.A.; Johnson, D.; Karnes, J.L.; O’Brien, P.C. Cool, warm, and heat-pain detection thresholds: Testing methods and inferences about anatomic distribution of receptors. Neurology 1993, 43, 1500. [CrossRef]

30. Wang, H.; Kim, M.; Normoyle, K.P.; Llano, D. Thermal Regulation of the Brain-An Anatomical and Physiological Review for Clinical Neuroscientists. Front. Neurosci. 2015, 9, 528. [CrossRef]

31. Brajkovic, D.; Ducharme, M.B. Facial cold-induced vasodilation and skin temperature during exposure to cold wind. Graefe's Arch. Clin. Exp. Ophthalmol. 2006, 96, 711-721. [CrossRef] [PubMed]

32. Kim, J.-H.; Seo, Y.; Quinn, T.; Yorio, P.; Roberge, R. Intersegmental differences in facial warmth sensitivity during rest, passive heat and exercise. Int. J. Hyperth. 2019, 36, 653-658. [CrossRef] [PubMed]

33. Hafner, J.; Lee, G.; Joester, J.; Lynch, M.; Barnes, E.H.; Wrigley, P.J.; Ng, K. Thermal quantitative sensory testing: A study of 101 control subjects. J. Clin. Neurosci. 2015, 22, 588-591. [CrossRef] [PubMed]

34. Inoue, Y.; Gerrett, N.; Ichinose-Kuwahara, T.; Umino, Y.; Kiuchi, S.; Amano, T.; Ueda, H.; Havenith, G.; Kondo, N. Sex differences in age-related changes on peripheral warm and cold innocuous thermal sensitivity. Physiol. Behav. 2016, 164, 86-92. [CrossRef] [PubMed] 